\title{
Paleo records as a guide for ecosystem management and biodiversity conservation
}

\author{
Daniele Colombaroli',2,3, C. Whitlock ${ }^{4}$, W. Tinner ${ }^{1}$ and M. Conedera ${ }^{5}$
}

\section{Projected climate and land-use changes challenge ecosystem management and conservation strategies to maintain biodiversity. Information on past vegetation and fire responses to human activity and climate variability helps identify which conservation targets (natural or cultural) best meet landscape management goals.}

Ecological mitigation and restoration efforts aimed at reducing the effects of excessive land use are currently under revision in light of climate projections that suggest significant changes in vegetation structure and composition in the coming decades (Diffenbaugh and Field 2013). Given the magnitude of projected change, future ecosystem dynamics are often difficult to infer on the basis of short-term observations alone (Willis and Birks 2006) and limited time perspectives may result in poor conservation decisions with unexpected consequences under new climate conditions (Gillson et al. 2013; Williams and Jackson 2007). The information offered by historical ecology and paleoecology, spanning centuries to millennia, reveals a range of ecosystem processes occurring at different spatial and temporal scales, as well as the extent to which present vegetation has been altered by past human activities. Understanding past ecosystem dynamics, and particularly the role of climate and humans, offers a baseline for interpreting current landscape conditions and helps set goals for conservation and restoration. Conservation actions will vary depending on (1) where the current landscape falls along a land-use gradient from pristine to intensely altered; (2) the motivation (or cultural values) to achieve more natural, or maintain, cultural landscapes; and (3) a cost-benefit analysis of pursuing particular strategies. We provide two examples of how paleoecology can help identify appropriate restoration targets and discuss the role of past environmental reconstructions for restoration, forest management and biodiversity conservation.

\section{Maintaining nearly pristine landscapes} Protected areas, like some of the large US national parks, are good examples of nearly pristine ecosystems, in that they support most of the species and ecological processes that existed prior to Euro-American settlement. In such settings, paleoecology provides critical insights about past ecosystem responses to a range of climate conditions and disturbance regimes in the absence of significant human interference (Millspaugh et al. 2000). Pollen records from across the Greater Yellowstone Ecosystem, for example, show that whitebark pine (Pinus albicaulis) was once more abundant and widely distributed than at present (Iglesias et al. 2015). During the early Holocene, when summers were warmer and drier and fires were more frequent than at present, this species grew at all elevations; its present restriction to high elevations is partly a result of the Holocene expansion of lodgepole pine (Pinus contorta; Fig. 1, top). Assessing whitebark pine's future based only on its present climate distribution underestimates its tolerance to warm summers and fire, and its intolerance of competitors. Today, the species is also under threat from the introduction of a non-native blister rust and warmer-than-previous winters. These novel conditions justify the need for careful monitoring of whitebark pine and the evaluation of any change against its response range to past climate and disturbance.

\section{Preserving biodiversity in}

\section{cultural landscapes}

Alpine landscapes have experienced a long history of human activity, ranging from
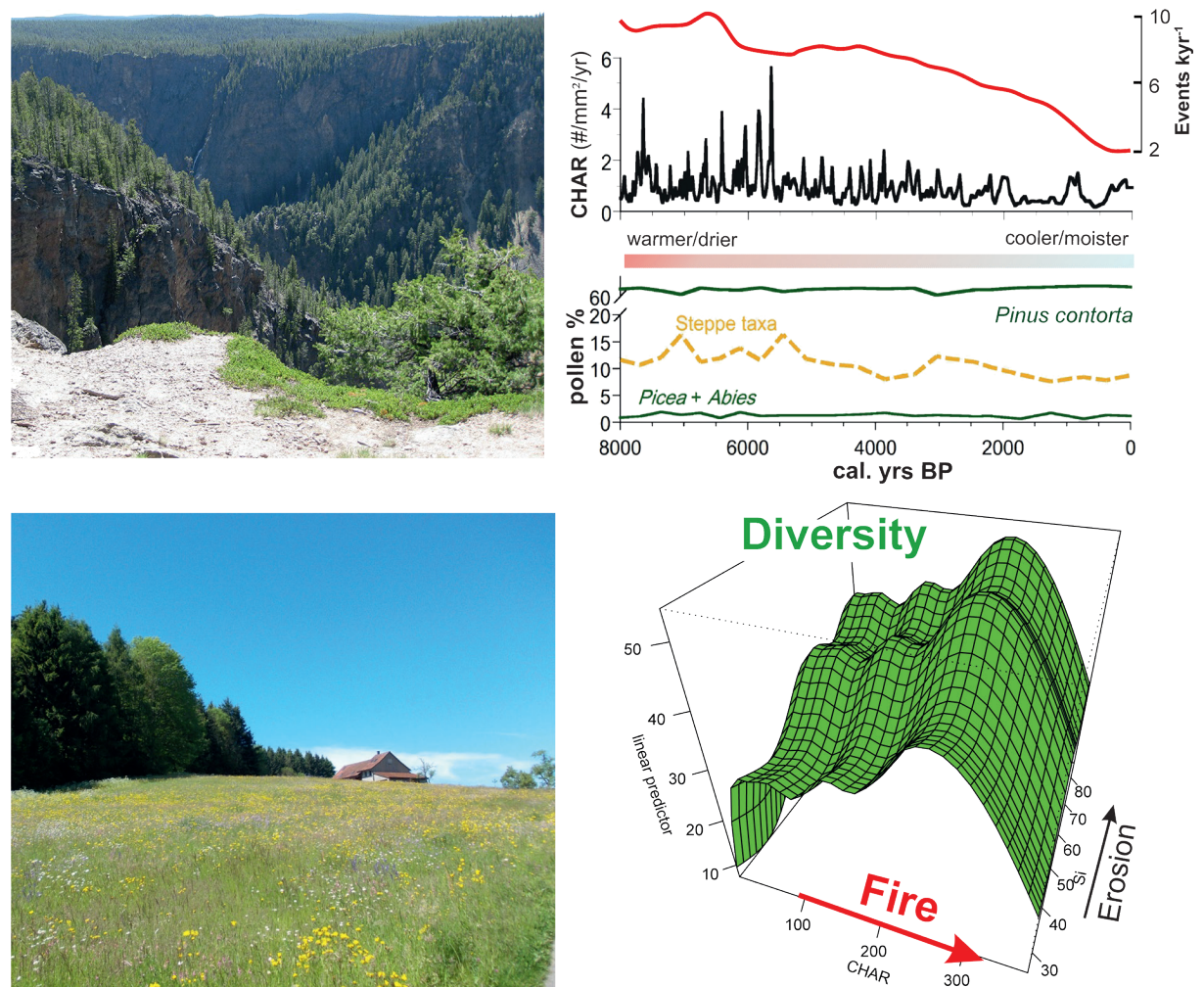

Figure 1: Top. Much of Yellowstone National Park is underlain by infertile rhyolite substrates that support lodgepole pine (Pinus contorta), a species that is also highly adapted to fire. Pollen and charcoal data suggest that lodgepole pine has maintained dominance in these geologic settings throughout the Holocene despite dramatic climate-driven changes in fire activity (Millspaugh et al. 2000; right panel, photo by CW). Bottom. Highly diverse meadows in mountain ecosystems offer important provisioning and cultural services (Broye Valley near Moudon, Switzerland, photo by DC). On the right: long-term records from the Valais (Central Alps) show variations in biodiversity (based on pollen data) as a function of fire (based on charcoal) and erosion (based on magnetic susceptibility). Plant diversity is maximized at intermediate levels of fire disturbances, in accordance with ecological theory. After Colombaroli et al. (2013). CHAR refers to charcoal accumulation rates, a measure of fire activity. 


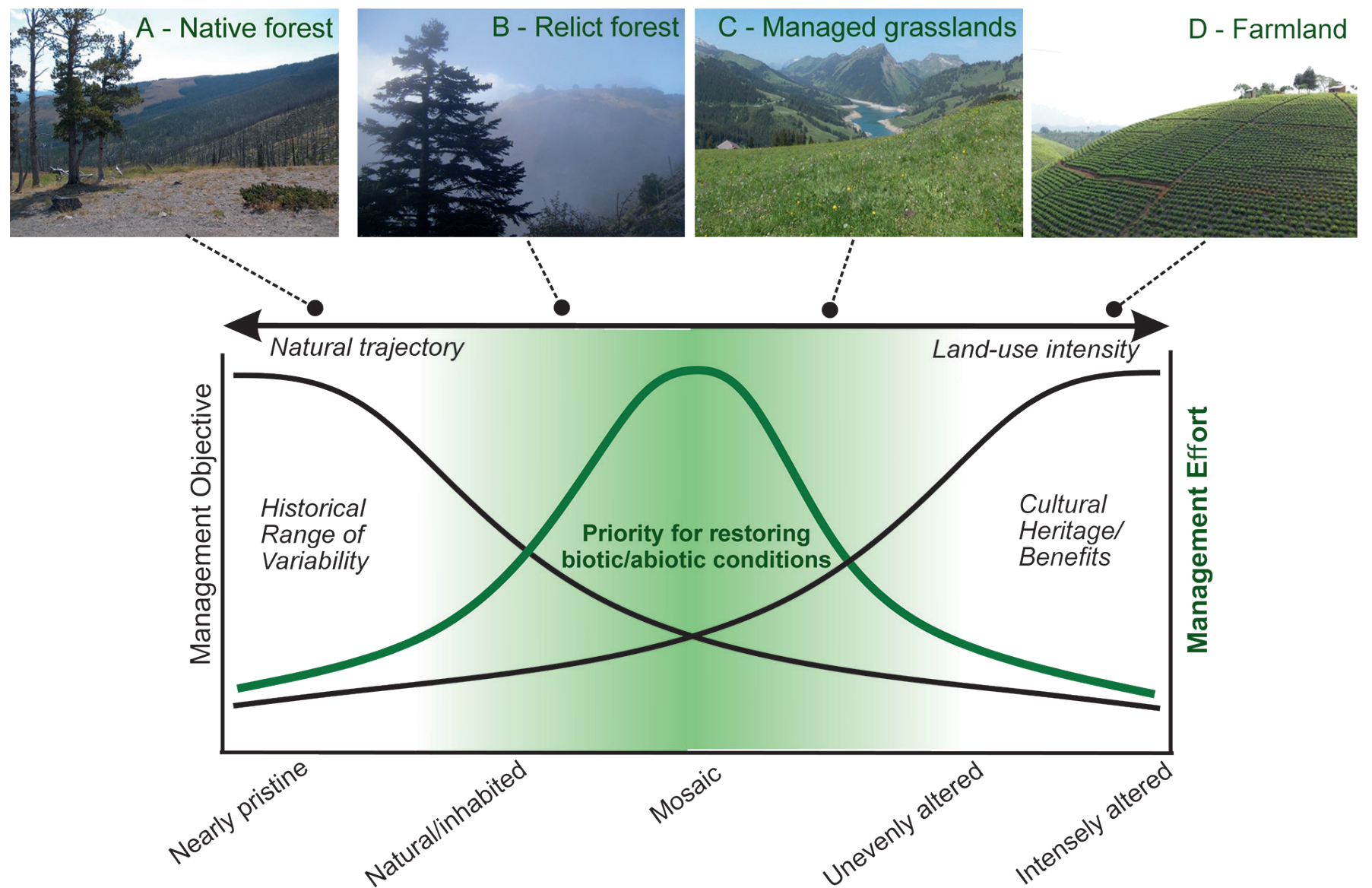

Figure 2: Top. Examples of landscapes with different levels of human alteration: (A) native Pinus contorta pine forest in Yellowstone National Park; (B) relict Abies nebrodensis forest in Sicily; (C) managed grasslands in the Alps; (D) tea crops in western Uganda (photos by DC). Bottom. Conceptual model showing management objectives across a gradient of landscape conditions, ranging from preserving historical range of variability in nearly pristine locations to promoting cultural benefits in intensely altered settings. The "landscape space" in the middle (green shading) highlights where pristine and humanized components co-exist and represent conservation opportunities for management objectives, for their potential to restore both historical range of variability and cultural values (based on Whitlock et al., in press).

For example, although the forests and grasslands in Switzerland are predominantly cultural landscapes, humans have and are altering their natural biodiversity differently. Alpine grasslands, prized for species richness, are now threatened by land abandonment and forest encroachment (Colombaroli and Tinner 2013). In contrast, forest diversity has been steadily depleted as a result of the deliberate reduction of some trees (e.g. Tilia, Fraxinus and Abies; Tinner et al. 2013) and the addition and promotion of others (Castanea, Taxus, Juniperus, Fagus, Picea; Conedera et al. 2017). The challenge for future conservation efforts in this region is to balance the legacies of past climate and land use against the conservation of cultural landscapes and ecosystems and their services.

\section{Incorporating ecosystem history \\ into conservation strategies}

Recognizing the degree of past landscape alteration can help determine the appropriateness and feasibility of management objectives that seek to restore naturalness or protect cultural heritage. Between nearly pristine conditions at one end and highly altered conditions at the other, landscapes in the intermediate part of the gradient support both natural and cultural components (Fig. 2). These intermediate landscapes pose conservation challenges - to support natural structure and diversity and at the same time maintain cultural values - but they also represent conservation opportunities (Lindenmayer and Hunter 2010). For example, disturbance-sensitive species often grow as isolated, relict forests in a matrix of humanaltered vegetation, facing high risks of extinction in some cases (e.g. Abies nebrodensis in Sicily; Fig. 2). Although the climate may be suitable for forest expansion, restoration requires fire suppression, grazing protection and removal of competing species to a level that may not be cost-effective or feasible (e.g. Henne et al. 2015). Deliberate intervention, careful management, and knowledge of landscape history can help guide realistic conservation planning.

Paleoecological information can play a key role in evaluating current ecosystem states, supporting (or disproving) the effectiveness of present conservation measures to balance specific targets (Fig. 2), and assessing future management strategies and vulnerability to climate change (e.g. Tinner et al. 2013). Capturing environmental and ecological variability requires knowledge of past climate legacies and human impacts, although such information is unevenly distributed and absent in some regions (e.g. tropical rainforests; Colombaroli et al. 2016). Research to better understand past fire activity, as it relates to climate, people and biodiversity, is the focus of the PAGES Global Paleofire Working Group (www.pastglobalchanges.org/ini/wg/gpwg2).

\section{AFFILIATIONS}

IInstitute of Plant Sciences and Oeschger Center for Climate Change Research (OCCR), University of Bern, Switzerland
${ }^{2}$ UGent Limnology research unit, Ghent, Belgium ${ }^{3}$ Centre for Quaternary Research, Royal Holloway University London, UK

${ }^{4}$ Montana Institute on Ecosystems and Department of Earth Sciences, Montana State University, Bozeman, USA

${ }^{5}$ Swiss Federal Research Institute for Forest, Snow, and Landscape WSL, Cadenazzo, Switzerland

\section{CONTACT}

Daniele Colombaroli: daniele.colombaroli@ips.unibe.ch

\section{REFERENCES}

Colombaroli D et al. (2013) Divers Distrib 19: 157-170

Colombaroli D et al. (2016) J Trop Ecol 32: 213-225

Colombaroli D, Tinner W (2013) Holocene 23: 1625-1634 Conedera M. et al. (2017) For Ecol Manage 388: 100-112 Diffenbaugh NS, Field CB (2013) Science 341: 486-492 Gillson L et al. (2013) Trends Ecol Evol 28: 135-142 Henne PD et al. (2015) Front Ecol Environ 13: 356-362 Iglesias V et al. (2015) Plos One 10, e0124439 Lindenmayer D, Hunter M (2010) Conserv Biol 24: 1459-1468

Millspaugh SH et al. (2000) Geology 28: 211-214 Tinner W et al. (2013) Ecol Monog 83: 419-439 Williams JW, Jackson ST (2007) Front Ecol Environ 5: 475-482

Willis KJ, Birks HJB (2006) Science 314: 1261-1265 Whitlock C et al. (in press) Conserv Biol, doi:10.1111/ cobi.12960 